\title{
Igavese sinitaeva maal II
}

Aado Lintrop

Konverents algas järgmisel päeval piduliku istungiga kõige suuremas geris. Sellele järgnes töö kolmes sektsioonis - munkhtenger ja šamanism (24 ettekannet), ajalugu, filoloogia ja kultuur (26 ettekannet), majandus, keskkond ja perekond (17 ettekannet). Kui programmi uskuda, oli lisaks kohalikele mongolitele ettekandjaid järgmistelt maadelt: 23 Jaapanist (sh neli mongoli või hiina nimega inimest), 17 Hiinast (neist 12 Sise-Mongooliast), neli Kalmõkkiast, kaks Koreast, kaks Venemaalt, üks Usbekistanist ja üks Eestist. Lisaks külalistena veel mõned jaapanlased ja Sise-Mongoolia esindajad, üks korealane ja üks grusiin. Kena rahvusvaheline seltskond ühe suure puudusega - palju inimesi ei osanud ühtki mulle arusaadavat keelt. Mitmed mongolid olid ära õppinud jaapani keele (ka härra Gerelbaatar), Sise-Mongoolia omad kõnelesid khalkha-mongoli ja hiina keelt, inglise keelt valdasid mingil määral korealased, jaapanlased ja venelased. Vene keelt oskasid peale minu, Khakha Šengelia ja Peterburi daamide mõned vanemad Mongoolia õpetlased. Ja kuigi ametlikeks töökeelteks olid inglise, mongoli ja jaapani keel, peeti enamik ettekandeid kahes viimases keeles ilma tõlketa.

Osalesin esimese sektsiooni töös. Minu ettekanne oli aegsasti tõlgitud khalkha-mongoli keelde, nii et need, kes inglise keelt ei osanud, said seda paberilt lugeda. Paraku ei mõistnud ma aga sõnagi sellistest ettekannetest nagu "Suure Mongoli Riigi traditsiooniline usund", "Tšingiskhaan kui mongoli rahva vaimne innustaja”, "Tšingiskhaani perioodi Mongoolia filosoofiline mõte”, "Munkhtengeri olemus ja Tšingiskhaani võim", "Munkhtengeri usund" jne. Viimase ettekandega esines muide tänapäeva Mongoolia tuntuim šamaan Dondog Bjambadorž, kellest kohe pikemalt juttu tuleb, sest esimese konverentsipäeva lõpetas tema ja ta abiliste poolt läbi viidud tule austamise rituaal. Dondog Bjambadorž (sünd 1947) on pärit Lääne-Mongooliast Hovdi aimagist, olkhoni hõimust (samasse hõimu kuulus Tšingiskhaani ema Hoelun). Vaimud hakkasid teda kiusama 1967. aastal. Dondog kannatas kaua haiguse käes. Vii- 
maks andis ta emapoolne onu Vančindorž talle pühitsetud parmupilli, millega Dondog hakkas vaime kutsuma. Onu juhendamisel sai temast šamaan. Sotsialistlikus Mongoolias šamaane muidugi ei sallitud ning šamanism säiliski vaid maa läänepoolses osas, mis asus pealinnast ja võimust kaugel.

Khalkha-mongoli šamanistlikke mõisteid:

böö (hääld buu) - šamaan

zairan-meesšamaan

udagan (udgan) - naisšamaan

böö mörgöl (buu murgul) - šamaanirituaal, traditsioon, pärand

šašin - usk, religioon

tenger - taevas

tsaagan tenger - valge taevas (neid on 55)

khar tenger - must taevas (neid on 44)

jeren jösön (jusun) tengeriin duudlaga - 99 taeva kutsumisloitsud takhil, takhilga-ohverdamine

örgöl (urgul) - ohverdamine, örgöl takhilga - loomohvri toomine

šivšleg - arstimissõnad, arstim

duudakh, ongod duudakh - loits

ongod orokh - ekstaas

örgöl ug - ohverdussõnad

guilt-palve

suld - hing, mis pärast inimese surma elab looduses

ami-hingushing, kehahing, reinkarneeruv

süns (suns) - taassündiv hing, meel, vari, vaim, viirastus

Rituaal toimus pärast päikese loojumist Erkhet Suldis spetsiaalsel platsil, mida ehtisid eriline tulealus ja kivikilpkonnade seljas lehvivad valged tugid ${ }^{1}$. Varem jäi mainimata, et terve turismibaas oli ehitatud nii, et meenutas ülalt vaadates soyombo tähestiku märki (seesama on ka Mongoolia lipul), mis tipneb poolkuu ja päikese kohal loitva leegiga. Kõnealune väljak moodustas selle märgi leegi-osa. Zairani jaoks oli kohale toodud laud ja tool. Laual võis näha mitmeid šamaani atribuute - seal oli värviliste nööride küljes rippuva puust nikerdatud abivaimu näoga kaunistatud parmupill, pronkspeegel, must tug, mitmed kotikesed ja nutsakud salapärase sisuga, kausikesed riisi ja pekitükkidega, viinapudel, kaks pokaali airagiga ${ }^{2}$ jne. Veel kaks lauda, mis kandsid erinevaid ohvriande ja joogiklaase, olid asetatud kitsal kivialusel põleva tule lähedale. Silma hakkas suurem tükk liha ja kauss pirukatega, mille peale oli puistatud kompvekke. Lisaks mainitud asjadele oli väljakul metallist tulekorv puudega. Zairan saabus koos mitme teda saatva abilisega - kõigepealt kolm altai stiilis (linnusulgedega ehitud) peakatete, lintidega kaunistatud šamaanirüüde, õlgadel rippuvate kosmilisi sümboleid kandvate keepide ja altai omadele sarnane- 


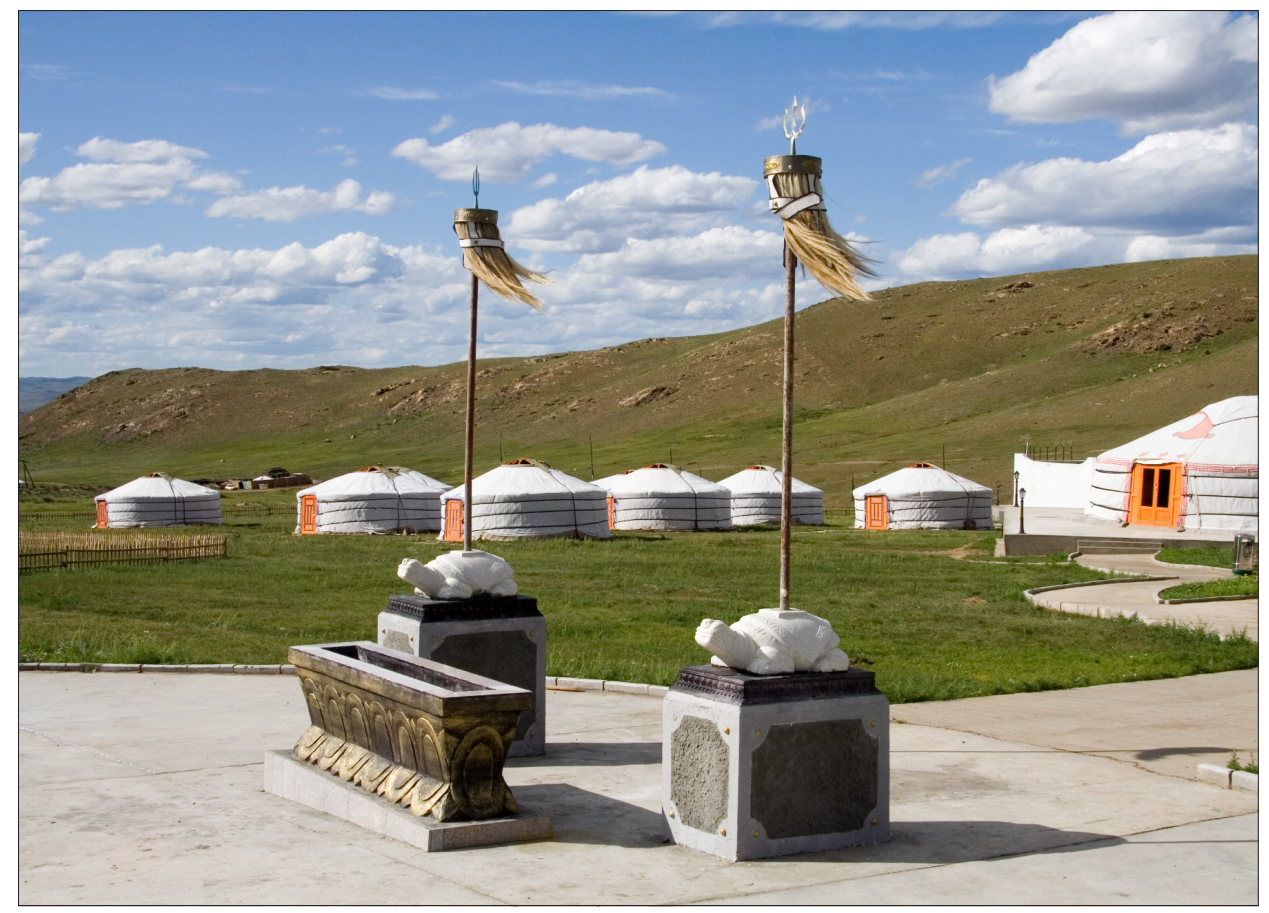

Valged hobusesabalipud (tugid) ja tulealus Erkhet Suldis. Aado Lintropi foto 2006.

vate trummidega tegelast, tõenäoliselt väiksemat šamaani või šamaaniõpilast (kellest vähemalt üks oli naine) ning veel paar meest ja naist, kes zairani ümber askeldasid, šamaane turvasid ja aitasid rituaali läbi viia. Kohe hakati ette valmistama tulele ohverdatavaid ande, mis asetati maha värvilistele nelinurksetele riidetükkidele (need lõigati kohapeal parajaks). Rituaal algas vaimudele kolme ilmakaarde (itta, lõunasse ja läände) airagi piserdamisega, mida sooritas üks kostümeeritud abiline. Seejärel pühitses Dondog enda ees laual olevaid toite, võttes iga kausi korraks kätte ning lugedes juurde mõned sõnad. Selleks ajaks, kui zairan trummi kätte võttis, oli väljakule kogunenud suurem osa konverentsist osavõtjaid ja turismibaasi töötajaid. Kohalikud inimesed põlvitasid ohvriandide taga vaibal ning hoidsid käes kollaseid siidsalle. Dondog alustas trummi saatel pikka loitsu, millega ühinesid ka trummiga abilised. Laulmise käigus liigutati trumme üles-alla ja kohati tekkis trummilöömise rütmis väike nihe, mis tekitas kerge kajaefekti. Siis asendati trummid parmupillidega, kusjuures jälle mängisid kõik neljakesi koos. Parmupillimängu käigus kostitati šamaane (või veelgi tõenäolisemalt neisse asunud vaime). Järgnes uus loits trummide saatel. Seejärel süütas noor abielupaar ohvritule ja šamaanitrummideta meesabilised hakkasid tulle ohverdama (galõn takhilga - tuleohver) valmispandud ande. Kõik juuresviibijad põlvitasid suures ringis ümber 
tule ja paljud tõstsid käed, peopesad ülespidi, taeva poole. Zairan tõusis oma kohalt ja õnnistas kollaseid siidsalle (võttes mõned neist enda kätte ja andes seejärel omanikele tagasi) ning jagas rahvale taldrikult pekitükke. Pärast tema lühikest sõnavõttu koondusid kõik tihedas ringis ohvritule ümber ja hakkasid selle ümber kõndides toitu tulle ohverdama. Paljud sirutasid peopesad lihtsalt tule poole. Siis õnnistas zairan mitmes reas põlvitavat rahvast, lüües inimeste peade kohal trummi ja lugedes palvet. Pärast seda istus ta taas oma kohale ning hakkas vastu võtma tähtsamate kohalviibijate tervitusi ja kingitusi, lubades neil vastutasuks nuusutada mingit kivipudelis olevat lõhnaõli või -ainet. Keegi ütles kommentaariks, et selline kingituste vahetamine olevat tavaliselt aastavahetusega seostuv komme. Kogu rituaal lõppes lõbusa tule ümber karglemisega, mille lõpuosas kostis kõlaritest juba diskomuusika.

Konverentsi teine päev veedeti ilusa ilma tõttu peamiselt õues, ja et šamanismi sektsioonis esines ka kolm jaapanlast, kes minu palvel rääkisid inglise keeles, sain ilusat loodust silmitsedes kuulata ka arusaadavaid ettekandeid. Konverentsi lõpetamiseks koguneti õhtul taas kõige suuremasse geri, kus kuulati pidulikke sõnavõtte, jagati aukirju, kuulati mongolite rahvamuusikat ja kõrilaulu ning viimaks vaadati uut, juubeliaastaks valminud filmi suure Tšingiskhaani tegudest.

Pärast kahte konverentsipäeva oli ette nähtud ekskursioon mongolite vanasse pealinna Karakorumisse. Väikest segadust tekitas asjaolu, et ühel mu toavõi õigemini gerikaaslasel oli ekskursioonisihina programmi kirjutatud Kharhorin, teisel Karakorum, nii et mõistatasime hulk aega, kas sõidame erinevatesse kohtadesse või mitte. Muidugi selgus, et Kharhorin on ajaloolise linna tänapäevane nimekuju. Erkhet Suldist sõitsime ära varsti pärast hommikusööki, et külastada Ulaanbaataris Mongoolia Ajaloo Rahvusmuuseumi ja Loodusajaloo Muuseumi. Esimene sisaldas väga huvitavaid eksponaate mongolite ajaloo ning eri etniliste gruppide rõivastuse ja eluviiside kohta. Esimese korruse saalis eksponeeritud spetsiaalnäitusel olid väljas suurkhaanide portreed, 13. sajandi diplomaatiline kirjavahetus, pitsatid jne. Kui nägin vitriinis koopiaid Rooma paavsti ja mõnede Euroopa kroonitud peade läkitustest mongoli suurkhaanidele ning khaanide vastuseid neile, meenus mulle Plano Carpini ${ }^{3}$ kirjeldus sellest, kuidas aastal 1246 kirjutati tatarlaste suurkhaani Güyüki läkitus paavstile:

Siiski ütlesime seda, mis näis meile kasulik, nimelt, et nad kirjutaksid tatari keeles ja tõlgiksid meile, aga meie paneme selle hoolikalt oma keeles kirja ning viime nii kirja kui tõlke paavstile. [---] Õndsa Martinuse päeval kutsuti meid teistkordselt, ja meie juurde tulid Kadak, Hingai, Bala ${ }^{5}$ ja paljud eespoolnimetatud kirjutajad ning seletasid meile läkituse sõnasõnalt ära. Aga kui me olime selle ladina keeles kirja pannud, sundi- 
sid nad meid seda eraldi lausete kaupa tõlkima, soovides teada, kas me ei eksi mõne sõnaga. Kui aga mõlemad kirjad olid valmis kirjutatud, sundisid nad meid kaks korda lugema, et meil juhuslikult ei oleks midagi vähem (kirjas) ja ütlesid meile: "Vaadake, et kõigest hästi aru saate, sest pole kasu sellest, kui te ei saa kõigest aru, kui peate sõitma nii kaugele maale." Ja kui me vastasime: "Saame kõigest hästi aru," kirjutasid nad läkituse saratseeni keeles ümber, et oleks võimalik, kui isand paavst soovib, leida keegi neis maades, kes seda loeb. (Mongolite ajalugu: 317-318).

Nii kirjutatigi omal ajal suurkhaanide läkitused mitme juriidiliselt võrdse tekstina, igaüks ise keeles, et vajadusel oleks võimalik üht teksti teise abil kontrollida. Kahjuks nappis muuseumis ekspositsiooni selgitavaid ingliskeelseid tekste, ka oli aega nii rikkaliku väljapaneku vaatamiseks antud liiga vähe.

Loodusajaloo muuseum nägi ajaloomuuseumist veelgi kulunum välja, kuid sisaldas traditsioonilistele loodusmuuseumidele kohustuslike fauna ja floora liigilis-ajalooliste ülevaadete kõrval ka suurepärast kogu Mongoolia aladelt leitud dinosauruste luustikest ja munadest, nende hulgas kaks Gobi kõrbest välja kaevatud tervikluustikku - muljetavaldav 15 meetri pikkune lihasööja Tarbosaurus, kes kaalus oletatavasti 4-5 tonni ja 8 meetri pikkune rohusööja Saurolophus. Pärast muuseume viidi meid paari suveniiripoodi ja sööma restorani, mis muidugi kandis Tšingiskhaani nime. Vastavalt kelnerite T-särkidel olevale kirjale, mis kuulutas, et loomad söövad rohtu, inimesed aga liha, kostitatigi meid enne pikka bussisõitu raskete lambalihatoitudega.

Sõit Karakorumisse oli pikk mitte niivõrd kilomeetrite poolest (umbes 450) kuivõrd ajaliselt. Mida kaugemale pealinnast, seda viletsamaks muutus maantee. Bussiaknast sai imetleda suurepäraseid maastikke lainjate mägede, nende jalamil asuvate geride ja loomakarjadega (veised, lambad, hobused, paaril korral ka kaamelid). Harva risustasid vaadet märgid industriaalsest tänapäevast, mida kohtas peamiselt suuremate asustatud punktide läheduses. Seetõttu polnudki teelt kõrvale vaadates väga raske ette kujutada, milline võis see maa välja näha Tšingiskhaani päevil. Nähtavasti avanesid tollastele ratsameestele üsna samasugused vaated, ainult, et kurenid ${ }^{6}$ olid suuremad kui tänapäeva karjakasvatajate laagrid ja ringi liikus palju relvastatud mehi. Teel ületasime kaks lauget mäekuru, kus tee kõrval kõrgusid hiigelsuured ovood palvelippudega ja jõudsime õhtuks poolkõrbelisse tsooni Elsen Tsarkhai luidete juures, kus ööbisime Altai Mongoli nime kandvas turismibaasis. Sellest mõnesaja meetri kaugusel oli karjakasvatajate laager, nii et soe öine õhk kandis meieni loomade häälitsusi ja lõhnu.

Järgmisel hommikul tuli sõita veel mitu tundi, enne kui Kharkhorin paistma hakkas. Tänapäeva Karakorum on Orkhoni jõe äärsete küngaste jalamil (kuid ikkagi peaaegu 1600 m kõrgusel) asuv umbes 9000 elanikuga pisike linn, 
mis suures osas meenutab küla. Arvatavasti sarnanes ta külaga ka 752 aastat tagasi, sest just ülestõusmispühade eel 1254 sinna jõudnud Wilhelm Rubruck ${ }^{7}$ kirjutas:

Karakorumi linnast olgu teie kõrgusele teada, et kui palee välja arvata, jääb see alla isegi Saint Denis's külale, aga Saint Denis' klooster on kümme korda suurem kui palee. Seal (linnas) on kaks kvartalit: üks on saratseenide oma, kus neil on turg ning kuhu sõidab kokku palju kaupmehi oukonna pärast, mis on pidevalt (linna) lähedal ja saadikute paljususe pärast; teine on kataide kvartal, kes kõik on käsitöölised. Väljaspool neid kvartaleid asuvad suured paleed, mis kuuluvad oukonna sekretäridele. Seal on kaksteist erinevate rahvaste templit, kaks mošeed, kus kuulutatakse Muhamedi seadust ja üks kristlik kirik linna servas. Linn on ümbritsetud savist müüriga, milles on neli väravat. Idapoolse värava juures kaubeldakse nisu ja teiste teraviljadega, mida siiski üpris harva sisse veetakse, läänepoolse värava juures mü̈̈akse lambaid ja kitsi, lõunapoolse juures müüakse härgi ja vankreid, põhjapoolse juures mü̈̈akse hobuseid (Mongolite ajalugu: 347-348).

Arheoloogiliste andmete põhjal oli iga linnavärava juures kivikilpkonna selga püstitatud kõrge steel. Karakorumi piirkonda asus Tšingiskhaan umbes aastal 1220 ja muutis selle kunagise naimanite pealinna oma Hiina vallutusretkede sõjaliseks keskuseks. Ta ise elas aga liikuvas palees ${ }^{9}$ linna lähikonnas. Pärast Tšingiskhaani surma valis Karakorumi lähedal kogunenud kurultai ${ }^{10}$ ta poja Ögedei uueks suurkhaaniks. Ögedei ehitas Karakorumi suures osas ümber aastaks 1235 ning muutis linna tähtsaks kaubanduskeskuseks. Ta lasi linna ehitada khaanilossi (Tumen Amugulang) ja käskis kõigil oma vendadel rajada linna palee. Karakorumisse saabus pidevalt eri maade saadikuid ja ametnikke, vene, gruusia ja armeenia ülikuid. Siiski armastasid ka Ögedei ja tema järglane Güyük elada sageli linna lähedal laagris. Ühe sellise laagri kohta, mida nimetati Sira Orda (Kollane Telk) ja kus toimus Güyüki khaaniks valimine, kirjutas Plano Karpini:

Kui me sinna saabusime, oli juba püstitatud suur telk, mis oli valmistatud peenest valgest kangast; meie arvates oli see nii suur, et võis mahutada kaks tuhat inimest, aga selle ümber oli tehtud puust piirdeaed, mis oli kaunistatud igasuguste kujutistega... Piirdeaia taga oli vene vürst Jaroslav Suzdalist ja mõned hiina ja solangi juhid, aga ka kaks Gruusia tsaari poega ning Bagdadi kaliifi saadik... Seal oli üle nelja tuhande saadiku, kelle hulgas olid need, kes tõid andamit ja need, kes tulid sultanite kingitustega, ning teised ülikud, kes tulid neile alistuma ning need, kelle järele oli saadetud ja need, kes olid maade asevalitsejad. (Mongolite ajalugu: 311-312). 
Ajaloolisest Karakorumist veel niipalju, et kaua selle hiilgus ei püsinud: 1260 . aastal rajas uus ja viimane suurkhaan Khubilai praeguse Pekingi kohale mongolite talvepealinna, ${ }^{11}$ seitse aastat hiljem aga viis kogu riigi keskuse sinna üle. 1388. aastal röövisid hiinlased Karakorumi paljaks, tapsid osa selle elanikest ja viisid umbes 70000 vangi.

Tänapäeva Kharkhorini peamine vaatamisväärsus on muistse mongolite linna kohale (ja väidetavasti osalt ka selle kividest) ehitatud Erdene Zuu (mngl erdeni - kalliskivi, aare; zuu - sada ${ }^{12}$ ) klooster, mille ehitamist alustati khalkhade valitseja Abtai-khaani initsiatiivil 1586. aastal. Kloostri ehitamine kestis vahedega kuni 19. sajandini. Erdene Zuu sai kahjustada 1680. aastate sõjategevuse käigus, kuid taastati 18. sajandil. Aastal 1872 oli kloostris 62 templit ja seal elas umbes 10000 laamat. Aastal 1937 lasi Mongoolia tollane kommunistlik juht Khorloogiin Tšoibalsan kloostri purustada rahvavaenlaste (sh laamade) vastase võitluse käigus. Hulk munki tapeti või küüditati. Säilisid kolm templit ja praegugi pilku püüdev kloostrit 400 x 400 m ruuduna ümbritsev müür 108 stuupaga. ${ }^{13}$ Kogu järgneva perioodi tegutses klooster muuseumina ja alles pärast sotsialismi kokkuvarisemist sai sellest uuesti ka kultusekoht. Praegu paikneb kloostri $160000 \mathrm{~m}^{2}$ territooriumil lisaks kolmele eraldi müüriga ümbritsetud Zuu templile ${ }^{14}$ veel tiibeti stiilis Lavrin Sum (kus toimuvad hommikused palvused) ning mõned väiksemad templid ja stuupad (kesksel kohal Kuldse Palve Stuupa). Kõige selle toreduse vaatamiseks oli aega umbes tund. Sisenesime kõigepealt Dalai Laama Templisse, mis ehitati 1675. aastal toimunud Abtai-khaani poja Altani dalai laama juures käimise mälestuseks. Templis olid klaasvitriinis mõned rituaalsed esemed: kellukesed, vadžrad ${ }^{\mathbf{1 5}}$ tütarlapse kolbast tehtud karikas jne. Maalitud kassettlagi oli kaunistatud kuuekroonleheliste õitega, mille sinises südamikus soyombo. Eraldi müüriga piiratud templi külastamise eest küsiti 3000 tugrikut, kuid asi tundus olevat kulutust väärt. Templitest vasak- või läänepoolne oli ehitatud Abtai-khaani ning ta poja poolt ja pühendatud täisealisele Buddhale. See tempel oli kahjuks restaureerimise tõttu suletud. Keskmine tempel kannab nimetust Gol Zuu või Zuu Buddha. Seal kõrgub kesksel kohal laps-Buddha kuju, kellest vasakul on Abida (õigluse jumal) ja paremal Otoch Manal (ravibuddha). ${ }^{16}$ Ukse kõrval vasakul seisab hirmuäratav puust sinise näoga Mahākāla ${ }^{17}$ kuju, peakate ehitud viie kolbaga, käes omapärane puust lokulaud (gandi gong), millega kloostris munki kokku kutsutakse. Paremal istub valge muula seljas veel hirmsam Šri Devī ${ }^{18}$ hoides ülemistes kätes mõõka ja saua, alumistes aga inimkolbast peekrit ja kolmikharki. Parempoolne tempel on pühendatud noorukieas Buddhale, kelle kujust vasakul on Janraisigi (Avalokitešvara), paremal aga gelugi koolkonna rajaja Tsongkhapa (1357-1419) kuju.

Teel kloostri idapoolsesse otsa möödusin väikesest suletud ukse ja lasuursinise katusega templist, mis olevat kõige vanem Erdene Zuusse ehitatud püha- 
koda ja Kuldse Palve Stuupast, mis püstitati 1799. aastal. Pildistasin ka mitmeid templikatuste detaile. Lavrin Sumi õues olid mõned palveveskid, lipukestega ääristatud jalgrajad ja hõreda niitmata rohuga murulapid. Paremat kätt asuvas hoones asus väike pood, kus müüdi palvelippe, siidsalle, heliplaate, raamatuid, fotosid. Hinnad olid paraku palju kallimad kui pealinnas. Lameda katusega Lavrin olevat ainus tiibeti stiilis ehitis terves Mongoolias. Selle parempoolne kõrvaluks oli avatud, sealt paistis laua taga istuv laama, kes võttis parajasti vastu jutulesoovivaid usklikke. Kuigi kloostril oli ka idamüüris värav, pääses välja siiski vaid lääneväravast. Selle poole tagasi tõtates jõudsin pildistada veel mõnda siniste lintidega ehitud kivi ja skulptuurielementi, mis võib-olla pärinesid veel Karakorumi ajast.

Bussi juurde jõudes selgus, et esialgu ei sõidetagi kuhugi kaugele, vaid minnakse vaatama suurt linnavärava juures paiknenud kivikilpkonna, mis asub kloostrist kirde pool. Kunagi raidkirjadega sammast kandnud kilpkonn on muljetavaldavalt suur - oma $130 \mathrm{~cm}$ kõrge ja vast kolme meetri pikkune, kael ehitud siniste, valgete ja kollaste siidsallidega. Kilpkonna taha oli kuhjatud väike ovoo. Samas lähedal paiknesid suveniirimüüjate lauad, kus pakuti üsna antiikse välimusega, kuid paraku osavalt järeletehtud kujukesi, nuge, teekanne, kausse ja muid metall-, puu- ja luuesemeid. Edasi tõkestas teed okastraat, selle taga paistis arheoloogide töömaa kaevistega, mille juures askeldasid ka mõned mehed nivelliiride või muude maamõõduinstrumentidega. Jäi mulje, et muistse palee asukohta kaitstakse hoolikalt turistide, aga võib-olla ka kohalike suveniirimüüjate eest.

Pärast lõunasööki linna lähedal Orkhoni kaldal kenas puudesalus asuvas turismibaasis hakkasime otsima kohta, kus pidi toimuma igavesele sinitaevale pühendatud šamaanirituaal. Ekselnud natuke linna läänest piiraval künklikul maastikul, sõitsime viimaks meile kogu aeg hästi paistnud künka tippu, mida ehtis kummaline silinderjas ehitis. Lähemale jõudes selgus, et silinder koosnes tegelikult kolmest suurele kiviplatvormile umbes kümnemeetrise vahega ringikujuliselt püstitatud kaarjast seinast, mille välisküljed olid kaetud punasest tellisest raamistuses maakaartidega, siseküljed paistsid olevat valgeks krohvitud ning mille harjal lehvisid valged tugid. Kaartidel kujutati mongolite ja nende eelkäijate (hunnide) riike. Seinte vahelt avanes vaade ringi keskel olevale suurele koonusekujulisele ovoole, mille tippu ehtisid ritvade otsas lehvivad erivärvilised kolmnurksed lipud. Künkatippu jõudes avanes äkki ka Orkhoni jõe lai roheline veerohke org ja ma mõistsin, miks oli see paik sobiv rändkarjakasvatajate riigi pealinnaks - orupõhja rohumaadel sõid praegugi suured loomakarjad, jõe taga künkanõlval valendasid gerid. Ronisin treppi mööda kiviplatvormile ja astusin seinte vahele sisenemiseks läbi kahe suitseva argalihunniku ${ }^{19}$ vahelt. Meenus Plano Carpini teade aastasadade tagant: 


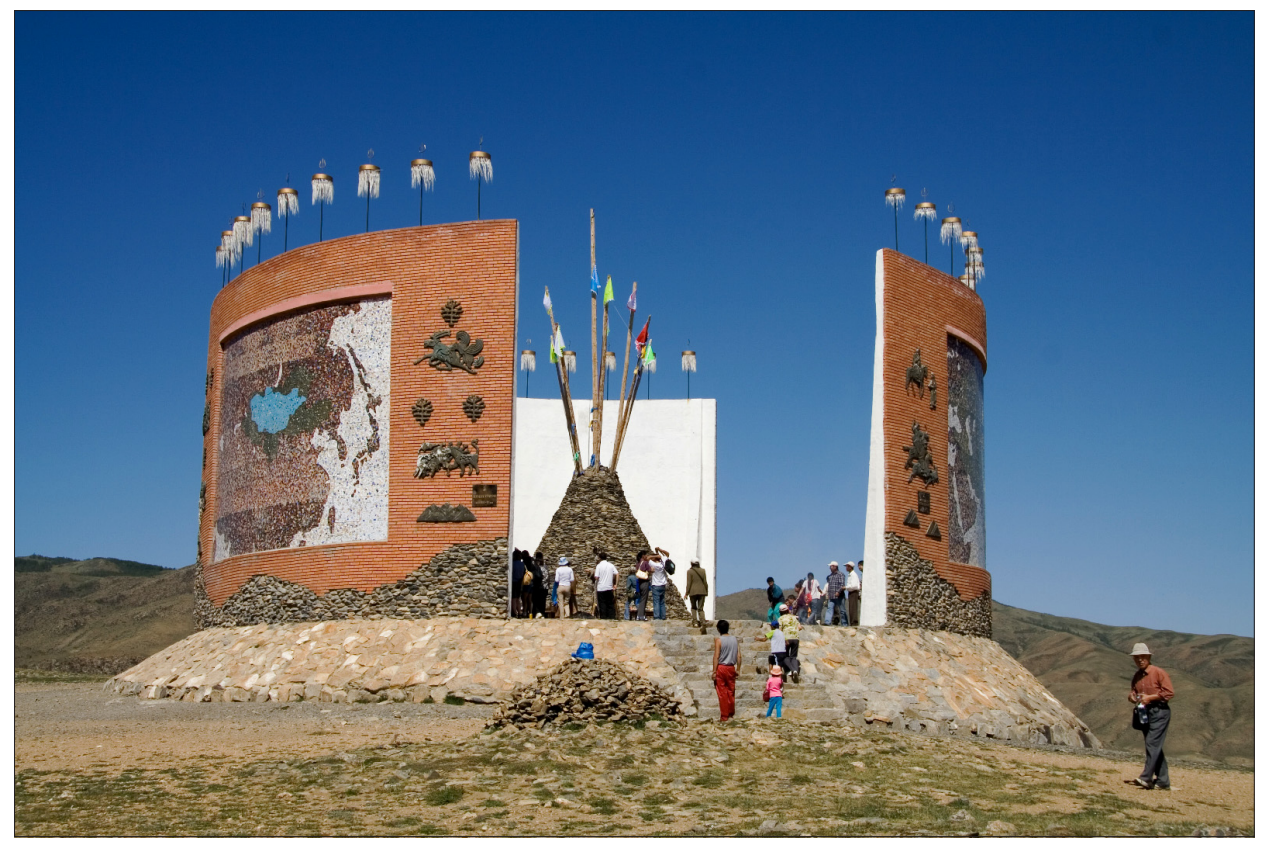

Mongolite kuulsusrikkale ajaloole pühendatud mälestusmärk Kharhorini lähedal. Aado Lintropi foto 2006.

Lühidalt öeldes usuvad nad, et tuli puhastab kõike; seepärast, kui nende juurde tulevad saadikud või aukandjad või ükskõik millised isikud, siis tuleb nii neil endil kui ka nende poolt toodud kingitustel minna läbi kahe tule vahelt, et puhastatud saada ja et nad ei korraldaks mingisugust mürgitamist või ei tooks kaasa mürki või mingit kurja (Mongolite ajalugu: 249).

Kaarjate seinte ääres istus ja seisis juba hulk inimesi, ovoo lõunapoolse külje ette oli pandud laud ohvriandidega. Kohal oli Dondog Bjambadorž oma meeskonnaga, abilistel rüüd juba seljas ja trummid käes. Oodati vaid meie saabumist.

Mönkh tengeriin šašin böö mörgöl (igavese sinitaeva usu šamaanirituaal) algas sellega, et zairan koos naise ja saatjaskonnaga sooritas mitu tiiru päripäeva ümber ovoo, lugedes sealjuures loitse oma samanimelisest raamatust ning piserdades ovood airagi ja viinaga. Piserdamist saatsid sõnad šoog, šoog, šoog, fraaside vahel kõlas ka khurai, khurai, khurai. Khurai seostub muidugi hurraaga, mis algupäraselt oli ju mongoli sõjameeste lahinguhüüd, šoog on aga huvitav selle poolest, et sarnased sõnad või häälitsused ( $t$ šok, tšök, tšekee) saatsid vaimudele (ka surnute hingedele) jookide piserdamist või toidu murdmist paljudel rahvastel alates Altaist ja lõpetades Udmurtiaga. Kui uskuda 
Dondogi raamatut, algas rituaal 99 taevale pühendatud loitsudega. Rahvas istus kogu rituaali aja, hoides peos ohvriande (riisi, kompvekke, küpsiseid, pirukaid) ning siniseid ja kollaseid siidsalle. Ühel vanemal mehel oli käes ka mala ${ }^{20}$. Pärast ovoo ümber tiirutamist istus zairan läänepoolse seina äärde paigutatud laua taha, millel olid juba eelmisest rituaalist tuttavad esemed ja võttis kätte parmupilli. Kaks kostümeeritud abilist põlvitasid vaibal zairani paremal käel ning mängisid koos Dondogiga parmupilli. Seejärel võeti trummid ning algas retsitatiivne loits trummimängu saatel. Seekord turvati loitsijaid selja tagant üsna hoolsalt. Pärast pikemat tõusvas tempos loitsude lugemist ning iga fraasi vahele khurei, khuraa, khuraa hüüdmist (mida kordas ka rahvas) hakkas zairan lauldes kordama mingeid sõnu, lastes nende vahel kuuldavale häälitsusi, mis kõlasid nagu khohh, khahh, khahh, khahh ehk rämedavõitu naer. Äkki lõi ta käed trummi üles tõstes laiali ja langes selili abiliste kätele. Abilised jätkasid veel veidi trummilöömist, zairan ainult häälitses ebamääraselt ja ohkas. Järgnevas vaikuses kõlas vaid ta raske hingamine. Zairan istus, trumm käes, ettepoole kummargil ja värises. Üks kostüümis abilistest tõusis ja hakkas ta kõrval piserdama eri suundades alkoholi. Siis võeti zairanil trumm käest (ta andis selle ära raske ohkega) ja peakate peast. Pikkamööda toibus ta transist. Tool nihutati kaugemale ja zairan heitis laua taha põlvili. Rahvas põlvitas Dondogi eeskujul samuti ja tõstis käed taeva poole. Zairani eestütlemisel loeti üheskoos loitsu või palvet, mis algas sõnadega Munkh tengriin khutšin dor mörgömu, biširmu, šutmu. ${ }^{21}$ Vahepeal kummarduti mitu korda maani, mille järel lugemine jätkus. Ja nii mitu korda. Pärast palvetamist tõusti ja asuti ovood, mis ilmselt kuulus mälestusmärgina riikliku kaitse alla, üle valama airagi ja viinaga. Kivide vahele aga torgati andideks mitmesugust söögipoolist. Selle toiminguga rituaal lõppes.

Tagasi Ulaanbaatarisse sõitsime sama teed mööda, kuid seekord läbisime selle ilma pikemate peatusteta umbes kümne tunniga. Et bussis igav ei hakkaks, esitasid eri rahvuste esindajad oma laule. Mina kui ainus soomeugrilane laulsin lisaks eesti rahvalauludele ka soome ja udmurdi omi. Väga heaks lauljaks osutus Takehiro Sato, kes esitas küll bluuse, kuid suutis isegi bussi helisüsteemist uskumatult korraliku hääle välja meelitada. Mongolid laulsid enamasti üheskoos laule, mis nii viiside kui üksikute arusaadavate sõnade poolest tundusid väga isamaalised. Jaapani sõbrad aga, v.a Takehiro ja üks vanem folkloristist professor, teadsid peamiselt lastelaule. Pealinna jõudsime hilisõhtul, Erkhet Suldi veidi enne südaööd.

Järgmise päeva jooksul lahkus enamik konverentsist osavõtnuid. Et mul oli lennukini veel mõned päevad aega, jäin samasse turismibaasi edasi elama. Tänu sellele õnnestus mul näha ka episoode mongolite naadanist. Seda rahvuspüha peetakse mitmel päeval juuli keskpaigas (tavaliselt 11.-13. juulini), 
kuid nüüd korraldati väike demonstratsioon Erkhet Suldi saabunud Taivani delegatsiooni auks. Et kohal olid ka vibulaskjad, õnnestus mul välja kaubelda õigus proovida korralikku mongoli vibu, mitte neid turistide poolt ära vaevatud laskeriistu, mida turismibaasis pakuti ja mille nool lendas parimal juhul vaid 20 meetrit. Vibu vinnastamine nõudis üsna suurt jõudu. Et sihtisin varasema kogemuse põhjal kõvasti üle märklaua (mis asus umbes 50-60 m kaugusel), lendaski nool kõrgelt üle selle. Siiski olin ainus võõramaalane, kes suutis üldse noole nii kaugele lennutada. Kohalikud laskurid aga tabasid kenasti märki. Selle taustal jääb mulle arusaamatuks John Manni kurtmine mongolite vibulaskmise allakäigu üle raamatus Tšingis-khaan, ${ }^{22}$ kus väidetakse, et tänapäeva mongoli vibulaskjad suudavad tabada märki hädavaevalt 30 meetri kauguselt. Muidugi, Tšingiskhaani ajaga võrreldes ${ }^{23}$ pole ka 70 meetrit kuigi palju, aga vibusportlasele on see märkilaskmiseks korralik distants. Külalistele (ka mõnele veel kohal olevale jaapanlasele) pakkus suurt huvi mongoolia maadlus, mida korduvalt võrreldi sumoga. Teatavasti on ju üks tugevaimaid jaapani sumomaadlejaid pärit Mongooliast. Ja loomulikult teadsid kõik ka Barutot. Minule oli uudiseks pigem maadlejate rituaalne tants enne ja pärast võistlust. Naadani kohustusliku elemendina peetud võidukihutamine hobustel ei pakkunud erilist elamust, huvitav oli pigem selle algus - võistlusest osa võtvad poisid (osa ilma sadulata) sõitsid tihedas grupis ja laulsid midagi omaette. Nii tiireldi oma veerand tundi pealtvaatajate lähedal. Võidusõit algas sel hetkel, kui esimene ratsanik oma hobuse galopile sundis.

Lisaks sportlikule meelelahutusele pakuti naadanil ka kunstilisi etteasteid. Head olid kondiväänajatest akrobaadid ning hobusepeaviiulite (moriin khuur) saatel kõrilaulu (khuumi) esitanud mehed. Näha õnnestus ka mongoli sõrmitsemistehnikas mängitavat tsitrit (yatag). Kõige krooniks oli aga tsamtantsu ${ }^{24}$ maskide etteaste, milles osalesid Vana Valge Mees, sõjajumal Jamsran, lind-deemon Khangard (sanskr Garuda) ja surnute jumal Tšojoo (sanskr Jama).

Ärasõidueelsel päeval õnnestus mul külastada Dondog Bjambadorži Ulaanbaatari äärelinnas asuvas šamaanigeris, kus ta argipäeviti patsiente vastu võtab. Vastuvõtule pääsemiseks tuleb ennast tavaliselt registreerida kõrvalhoones asuvas kontoris (ja tõenäoliselt maksta ka visiiditasu). Kuna läksin šamaani juurde koos Gombodoorovyn Gerelbaatariga, jäi see episood vahele. Eelmisel päeval ütles Gerelbaatar, et tal on poja pärast šamaani poole asja ning küsis, kas tahan kaasa minna. Ma muidugi tahtsin. Pealegi tundsin ennast pärast raskeid lihatoite ja pikki bussisõite üsna kehvasti. Nii astusimegi koos Gerelbaatari ja ta kaheksa-aastase pojaga geri uksest sisse. Zairan istus vasakut kätt seina äärde paigutatud laua taga, seljas Tšingiskhaani pildiga T-särk, ja vestles just ühe abivajajaga. Ootamas olid veel mõned nais- ja meespatsiendid. Jõudsin märgata, et seintele olid riputatud kostüümid, peakatted, vutlarites 
šamaanitrummid ja muud vajalikud asjad. Sissepääsu vastas seinal (ühtlasi ka aukohal) rippus Tšingiskhaani portree. Geri keskel seisis väike raudahi, mille pealt paistis taldrik mingite põlenud taimevartega (tõenäoliselt puju). Olles ühe patsiendiga lõpetanud, kutsus zairan laua juurde Gerelbaatari ühes pojaga. Poeg pandi toolile istuma, selg ukse poole. Vestelnud veidi poisi isaga, piserdas zairan vaimudele alkoholi, võttis laualt mitmeharulise piitsa moodi asja ning tõmbas sellega poisil mitu korda sümboolselt üle selja, ise loitsusõnu lugedes. Seejärel andis ta nii isale kui ka pojale nuusutada lõhna mulle juba tuttavast kivipudelist ja saatis nad siis Tšingiskhaani pildi ette, kus mõlemad maani kummardades palvetasid. Seejärel oli kord minu käes. Öeldi, et võin zairanilt küsida, mida iganes tahan. Tõlgiks üritas olla Tõvamaalt Dondogi juurde abi otsima tulnud keskealine naine. Küsisin siis Kharkhorinis nähtud rituaali tähenduse kohta, mispeale zairan lehvitas tuttavat raamatut, ${ }^{25}$ öeldes: Loe seda, siin on kõik kirjas. Tore, oleksin juba lugenud, kui keelt oskaksin. Siis küsisin, kui palju on mongoli šamaanil keskeltläbi abivaime. Zairan vastas, et neid on umbes kolmkümmend kuni nelikümmend. Aga temal, küsisin. Täpset arvu reetmata vastas ta, et nende hulgas on seitse esivanematelt päritud vaimu. Seejärel kurtsin oma halba tervist. Zairan püüdis täpsustada, kuidas ja kust nimelt mul kõht valutab, kallas vaskkausikesse veidi viina, pistis sinna kaks põlevat tikku ja käskis viina ära juua. Pärast ütles ta, et nii leevendas ta mu häda ainult ajutiselt, kestvama efekti saavutamiseks tuleb mul minna poodi ja tuua suhkrut. Läksingi kuulekalt koos Gerelbaatariga lähedal asunud kauplusse, ostsin paki tükisuhkrut ja Gerelbaatari soovitusel veel pudeli viina šamaanile külakostiks. Ka õpetati mind, et on viisakas anda zairanile veidi raha. Summa polevat oluline, küll aga rahapaberi andmine ise. Kui jõudsin tagasi geri, kutsuti mind kohe laua juurde. Märkasin, et seekord eraldati mind teistest patsientidest sirmiga. Andsin viinapudeli ja suhkrupaki šamaanile, kes pudeli kohe lahti tegi, veidi viina kaussi valas ja kolme ilmakaarde piserdades sellega vaime kostitas. Seejärel luges ta loitsu, pani kaks tikku põlema, tegi nendega tiiru mu näo ees (nagu tahaks neid mulle ulatada) ja toppis siis pudelisse. Samamoodi võttis ta kaks põlevat tikku, tegi nendega tiiru mu pea kohal ja pani need suhkrutükkide peale. Viinapudeli andis ta mulle tagasi, küsides, kas ma äkki pole mingeid asju kellegi võõra inimese kätte andnud. Ütlesin, et selline asi võib küll juhtunud olla. Võta see pudel, ütles ta, piserda siit iga kord vaimudele enne seda, kui rituaali läbi viima hak$k a d$. Siis andis ta ka pealt veidi kõrbenud suhkrupaki ja käskis iga kord enne sööki pakist üks tükk suhkrut sisse võtta. Sellega minu ravimine lõppeski. Pean tunnistama, et pooliku viinapudeli jätsin Erkhet Suldis voodi taha, olles enne rikkalikult piserdanud igasse ilmakaarde (ka põhjakaarde - surnutele). Suhkrut aga võtsin kuulekalt sisse ja ülejäägi tõin koju kaasa. Tervis igatahes 
paranes ning tagasiteel, mis kulges eriliste seiklusteta (kui Pekingi sääserohkes hotellis veedetud öö välja arvata), tundsin ennast jälle hästi.

\section{Kommentaarid}

1 Tug - mongoli hobusesabalipu või -embleemi üldnimetus. Antud juhul oli tegemist tsaagan suldidega - Tšingiskhaani ajast pärit rahuaegsete lippudega. Mongolite suurkhaani ees kanti rahuajal alati üheksat sellist lippu. Sõjakäigul asendasid neid mustad lipud (khar suld).

2 Kääritatud hobusepiimast valmistatud alkohoolne jook.

3 Giovanni da Pian del Carpine, ka Johannes de Plano (1180-1252), frantsiskaani munk, kelle paavst saatis oma legaadina mongolite suurkhaani juurde. Alustas teed Lyonist 16. aprillil 1245 ning jõudis 22. juulil järgmisel aastal khaani laagrisse Karakorumi lähedal.

${ }^{4}$ Güyük, ka Guyuk, Kuyuk - Tšingiskhaani lapse Ögedei poeg, valitses aastail 12461248.

5 Suurkhaani valitseja ja sekretärid.

${ }^{6}$ Mongolite hõimu või väiksema grupi laager ringikujuliselt paigutatud geridega (khuree - ring), mille keskel asus pealiku või khaani ger.

7 Ka Willem van Ruysbroeck, Guillaume de Rubrouck, Willielmus de Rubruquis sünd 1220 Flandrias Rubrouckis, flaami päritolu frantsiskaani misjonär ja maadeuurija. Saatis Louis IX seitsmendas ristisõjas ning alustas tema korraldusel mais 1253 Konstantinoopolist misjoniretke mongolite juurde. Jõudis Karakorumisse lihavõtteks 1254 ja tagasi Euroopasse järgmise aasta kevadeks. Julguse katseks pöörata mongolite suurkhaan ristiusku andsid kuuldused khaani õukonnas viibivatest kristlastest (kes osutusid nestoriaanideks) ja Euroopas levima hakanud müüt kaugel idas asuvast vägeva kristliku preesterkuninga Johannese riigist (viimane leidis hiljem laialdast kajastamist Marco Polo reisikirjas).

${ }^{8}$ Saint Denis, tänapäeval üks Pariisi põhjapoolsetest eeslinnadest, kus asus ka samanimeline kirik ja klooster, mis oli keskajal väga kuulus tänu selle rajaja frangi kuninga Dagobert I (603-639) antud privileegidele. Saint Denis' basiilikasse on maetud enamik prantsuse kuningaid.

9 Loomulikult oli see vaid luksuslik ger või suur telk, mis vastavalt laagri kolimisele ühest kohast teise üle viidi.

${ }^{10}$ Kurultai - mongoli pealike ja khaanide sõjalis-poliitiline nõukogu, kuhu kuulusid allutatud hõimude vanemad ja väejuhid.

11 Seal asus Jini dünastia pealinn Zhongdu, mille mongolid põletasid maha 1215. aastal. 1264. aastal otsustas Khubilai-khaan linna uuesti üles ehitada oma riigi pealinnaks. Linn, mida siis tunti nimega Khanbaliq (Marco Polol Cambuluc) või hiinapäraselt Dadu (Tatu), sai Khubilai-khaani rajatud Yuani dünastia (1271-1368) pealinnaks. Mingi dünastia ehitas linna uuesti üles ja andis sellele algul nimeks Shuntian, pärast aga Peiping.

${ }^{12}$ Kontrollimata andmetel tähendab zuu lisaks tiibeti keeles auväärset.

${ }^{13}$ Sama palju on helmeid budistlikes palvehelmestes. 
${ }^{14}$ Baruun (lääne) Zuu, keskmine Gol (peamine) Zuu ehk Zuu Buddha ja Zuun (ida) Zuu. Tegelikult on kompleksis veel kaks templit - läänes Tsamba ja idas Ajuši tempel.

${ }^{15}$ Vadžra - algselt jumal Indra välgunoole sarnane purunematu relv, hiljem ka teemant. Budismis väljendab virgumise purustamatut ja hävitamatut loomust. Sümbolina kujutatakse erilise kahe poolega sauana, millel on kummalgi pool üks, kolm, viis või üheksa haru. Sümboliseerib aktiivsust, mehelikkust, kaastunnet, kelluke aga passiivsust, naiselikkust ja mõistmist.

${ }^{16}$ Bhaic-ajyaguru - Ravimise Isand, ajaloolise Buddha Šākjamuni raviv aspekt.

17 Sanskriti maha - suur ja kala - must. Vadžrajaanas väga erinevalt kujutatavad Mahākālad on raevukad jumalused - seadusekaitsjad (dharmapāla).

18 Tumesinine naissoost seadusekaitsja, Mahākāla kaasa, dalai-laama ja pantšenlaama kaitsejumalus.

${ }^{19}$ Argal - kuivanud hobusesõnnik, mida kasutatakse lõkkematerjaliks.

${ }^{20}$ Palvehelmed, mida kasutavad nii hinduistid kui budistid. Harilikult koosneb mala 108 helmest.

${ }^{21}$ Umbes: Igavese sinitaeva väge palume, austame, usume...

${ }^{22}$ John Mann. Tšingis-khaan. Tallinn: Pegasus 2006.

${ }^{23}$ Teatavasti leiti Venemaalt Nertšinski lähedalt 19. saj algul aastaist 1224-1225 pärinev raidkiri tekstiga: Kui Tšingiskhaan pärast Sartauli rahva vallutamist kogus kõik Mongoli riigi nojoonid Bukha-Sudz̈khai juurde, lasi Jesünge (vibust) kaugusele 335 aldi. Et ald on umbes $160 \mathrm{~cm}$, on Tšingiskhaani vennapoja kuulsa noolelennu pikkus umbes 536 meetrit.

${ }^{24}$ Tsam - tiibeti budismis rituaalne maskidega tants. Sageli on tsam-tantsude moraaliks mitte kahjustada teadvusega olendeid. Nende vaatamine toovat õnnistust. Neid peetakse ka meditatsiooni vormiks ja ohvrianniks jumalatele.

${ }^{25}$ See raamat (Зайран Д. Бямбадорж. Мөнх тэнгэрийн шашин бөө мөргөл. 2006 он.) oli koos teeside ja artiklikogumikuga minu konverentsimapis.

\section{Kirjandus}

Mongolite ajalugu = История монголов. Москва: АСТ: Транзиткнига 2005.

\section{Summary}

\section{On the Land of Eternal Blue Sky}

\section{Aado Lintrop}

The second part of Aado Lintrop's travelogue from a visit to the conference on ancient Mongolian religion in Mongolia. 